Proyectos Corporativos Texto: Alex Brahm Santiago, Chile

El sistema de concesiones de vías urbanas expresas cambió la manera de recorrer la ciudad y relacionarse con sus lugares, y también produjo la aparición de nuevos programas y problemas para la arquitectura: centrales administrativas y de control, atención de emergencias o casetas para monitoreo. En parte recintos de servicio, en parte imagen corporativa, estas construcciones ya se han incorporado al imaginario urbano. ¿Cuál es su capacidad de intervenir positivamente el paisaje de la ciudad?. Palabras clave: Autopistas urbanas, equipamiento urbano, vías concesionadas,
carreteras, vialidad.

The concessions system for urban highways has changed the way we move about the city and relate to it, and has also produced new programs and issues for Architecture, with administrative and supervisory centers, emergency services or monitoring booths. Part service centers, part corporate image, these buildings have blended into our vision of the city. Can they have a positive impact on the urban landscape?

Key words: Urban highways, urban facilities, concession roads, highways,

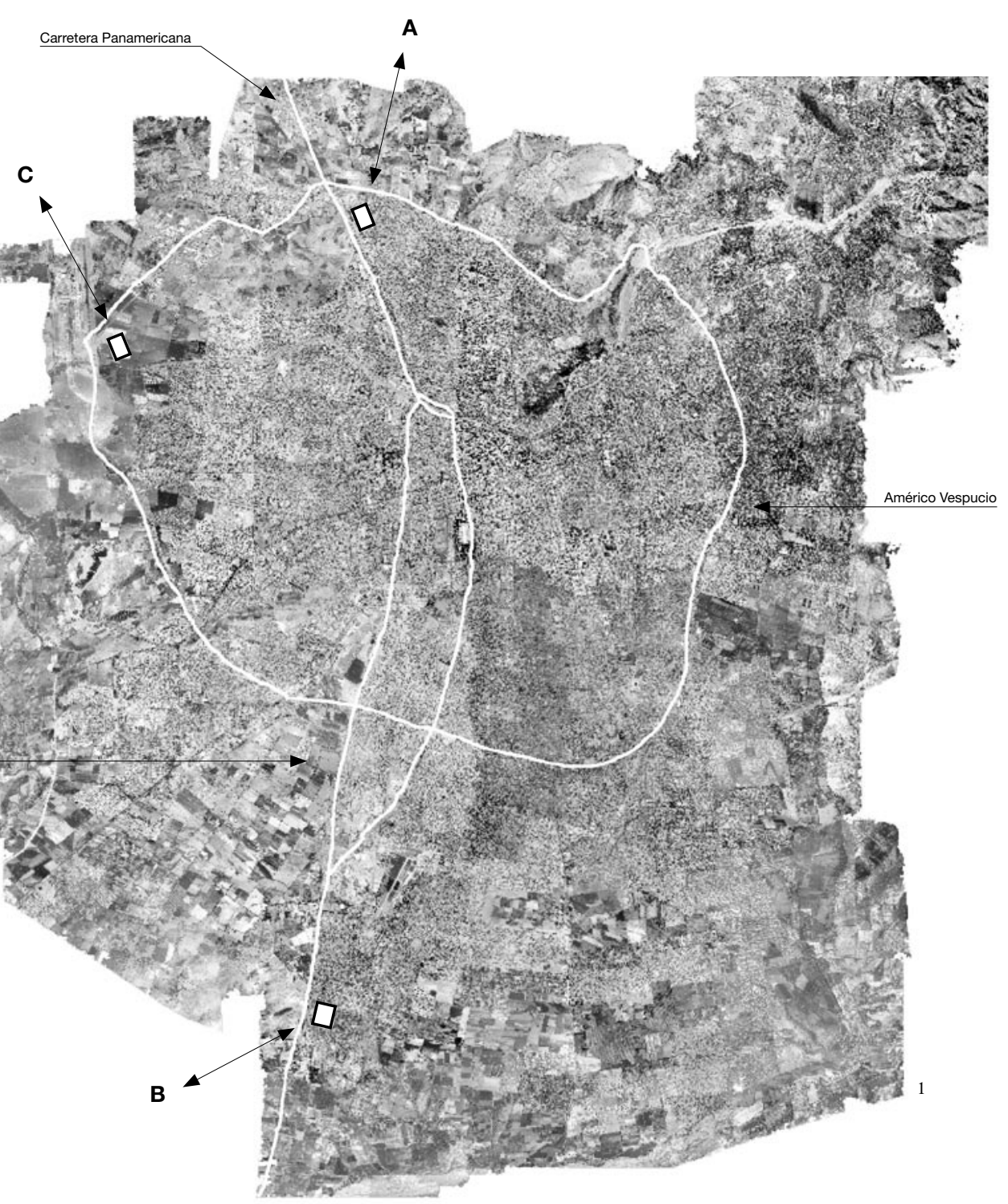

\title{
Autopistas urbanas
}

\section{El contexto general}

Durante los últimos 4 años nuestra oficina ha desarrollado diversos proyectos de arquitectura para Autopista Central, Vespucio Norte Express y Vespucio Sur, 3 de las 4 empresas concesionarias de autopistas urbanas que operarán en Santiago de Chile.

Aunque no tuvimos ninguna participación en los proyectos viales, ni en sus relaciones con la ciudad, el trabajo desarrollado para estas empresas nos permitió conocer un poco más del procedimiento adoptado para la ejecución de estas enormes obras.

En síntesis, el Ministerio de Obras Públicas elabora las BALI (Bases de Licitación), documento que fija las condiciones del llamado a propuesta y el PRID (Proyecto Referencial de Ingeniería de Detalles), documentos que definen la totalidad de las obras a ejecutar. Las empresas que postulan a la licitación evalúan estos antecedentes y presentan sus ofertas.

A otra escala, operan de forma similar a la de un llamado a propuesta para la ejecución de un edificio cualquiera, en el cual el MOP es el encargado del proyecto y las concesionarias actúan como las constructoras que ejecutarán las faenas.

Lamentablemente, ni las BALI ni el PRID incorporan con profundidad temas arquitectónicos relevantes para nuestra ciudad y replican un ya antiguo esquema en el cual las distintas disciplinas y la comunidad lejos de actuar coordinadas, se presentan como antagónicas.

No cabe duda que lo principal de estos proyectos es lo referido a la ingeniería de transporte y al proyecto vial, aspectos que suponemos bien elaborados, ya que no contamos con información ni con calificación profesional como para emitir una opinión seria al respecto.

Pero no es menos cierto que un trabajo profundamente integrado con otras disciplinas y con la comunidad, podría haber contribuido, no sólo a ahorrar tiempo, combustible y accidentes en los desplazamientos viales, sino que además a cambiarle drásticamente el aspecto a grandes zonas de la ciudad.

En efecto, la enorme superficie de parques, la cantidad de equipos de iluminación, las pasarelas peatonales, los puentes, los pasos bajo nivel, las calles de servicio y otros, además de cumplir con las especificaciones viales (seguridad, velocidad de desplazamientos, durabilidad y mantenimiento), eran una increíble oportunidad para que nuestra ciudad también mejorara fuertemente el diseño y la calidad de sus espacios públicos.

La envergadura de las obras y su distribución espacial involucran a casi todas las comunas del Gran Santiago. Haberlas diseñado con profundidad 


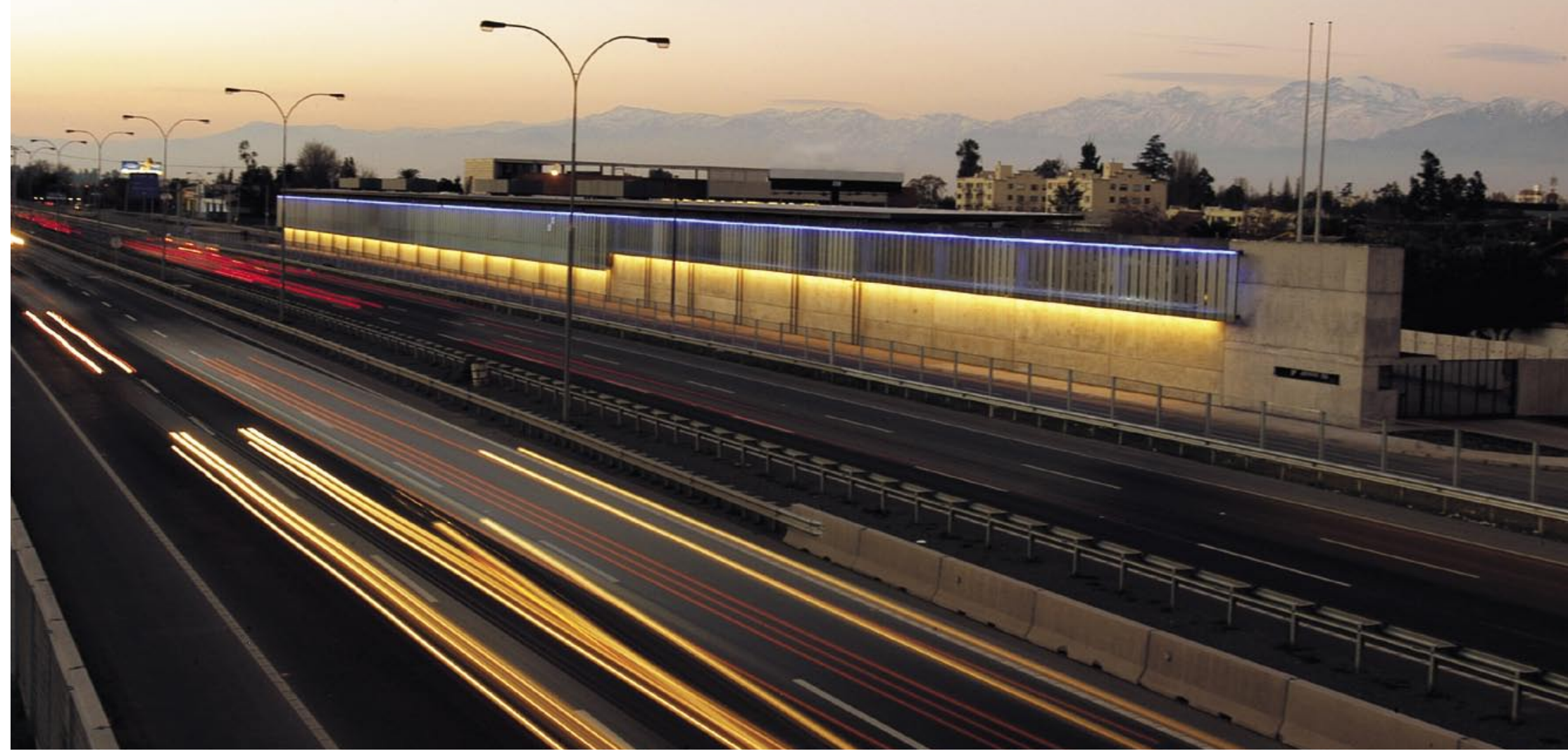

podría haber generado un nuevo paisaje urbano para nuestra ciudad, podría haber contribuido con mucho más fuerza a disminuir las desigualdades sociales aportando nuevos espacios públicos de calidad en áreas sumamente pobres, y quién sabe qué otros beneficios adicionales se podrían haber imaginado y ejecutado si se hubiera abordado el proyecto con mayor amplitud y participación desde el inicio.

Estamos conscientes que este procedimiento de concesiones no es ni ha sido fácil. Pensamos que lo ejecutado es un gigantesco avance y creemos que, tal como las obras de carreteras al sur y al norte del país, una vez en funcionamiento, nos dejarán a todos muy complacidos de ocupar menos tiempo en desplazarnos.

Sólo queda esperar que en el futuro cercano se puedan agregar nuevos recursos para mejorar, completar y/o rehacer la mayoría de las "obras anexas", que claramente no están en el mismo estándar de calidad que lo alcanzado por el proyecto vial, y aportar todo lo que podamos desde nuestra profesión para que este procedimiento no se repita en las nuevas inversiones en infraestructura.

Los proyectos para las empresas concesionarias Conocido el contexto general, llama aún más la atención la buenísima relación profesional que establecen las empresas concesionarias con sus asesores (arquitectos en este caso), cuando se trata de los proyectos privados, en los cuales el MOP tiene una injerencia menor.

Fuera del proyecto vial propiamente tal, las concesionarias de autopistas urbanas deben ejecutar diversos edificios de equipamiento para operar en forma eficiente: los edificios corporativos, que contienen las oficinas técnicas, administrativas y comerciales, los centros de atención de emergencias y mantenimiento, y varias edificaciones menores que detallaremos más adelante. Para estas edificaciones, reviertan o no al MOP después de los treinta años de concesión, el tratamiento es completamente diferente.

En todos los casos -Autopista Central, Vespucio Norte Express y Vespucio Sur- los encargados de dirigir estos proyectos fueron los gerentes generales, directores técnicos o personeros de la más alta jerarquía de la empresa. En la mayoría de los casos se trataba de ejecutivos europeos (españoles, suecos y alemanes), habituados a un estándar más alto en calidad de construcción, con una buena base de conocimientos generales de arquitectura y con gran respeto por nuestra disciplina.

En otras palabras se trata de un cliente culto, que tiene clara conciencia que sus inversiones en infraestructura deben durar a lo menos 30 años y que cuenta con el capital necesario para ejecutar obras de alta calidad constructiva y arquitectónica.

Estas consideraciones, además de una relación profesional de gran respeto, pero también de gran exigencia (calidad técnica de las soluciones propuestas, rigor en los plazos de entrega de proyectos y precisión en las estimaciones de inversión) fueron determinantes centrales de la calidad de los proyectos desarrollados y reafirmaron nuestro interés en el desarrollo de edificios de gran simpleza formal y constructiva. La necesidad de flexibilidad programática de las edificaciones, especialmente relevante al tratarse de empresas nuevas y con un horizonte de al menos 30 años de funcionamiento va en la misma línea. Esto nos ayudó a proponer edificios de programa genérico y no determinados por requerimientos esencialmente cambiantes.

A continuación se exponen algunos edificios desarrollados para Autopista Central y Vespucio Norte Express que se encuentran terminados y en plena operación. Las edificaciones para Vespucio Sur (un edificio corporativo y casetas técnicas) están actualmente en etapa de ejecución. ARQ 
Centro de atención de emergencias norte Al extremo norte de la carretera, en la comuna de Conchalí, se proyectó un centro que redujera los tiempos de respuesta para emergencias en la vía. Éste, de menor envergadura, contiene sólo vehículos de emergencia y bodegas en primer nivel, y oficinas, servicios y sala de descanso para operadores en el segundo.

Dada la configuración del terreno y los accesos y salidas de la vía expresa, a diferencia del CAE Sur, los vehículos de emergencia se conectan directamente a la vía expresa y reservan áreas de estacionamientos al norte y sur del edificio.

El tipo estructural y la configuración arquitectónica es similar al CAE Sur, utilizándose el frontón de la cubierta de los vehículos como protección solar y de ruido, construido en plancha perforada en reemplazo del Profilit.
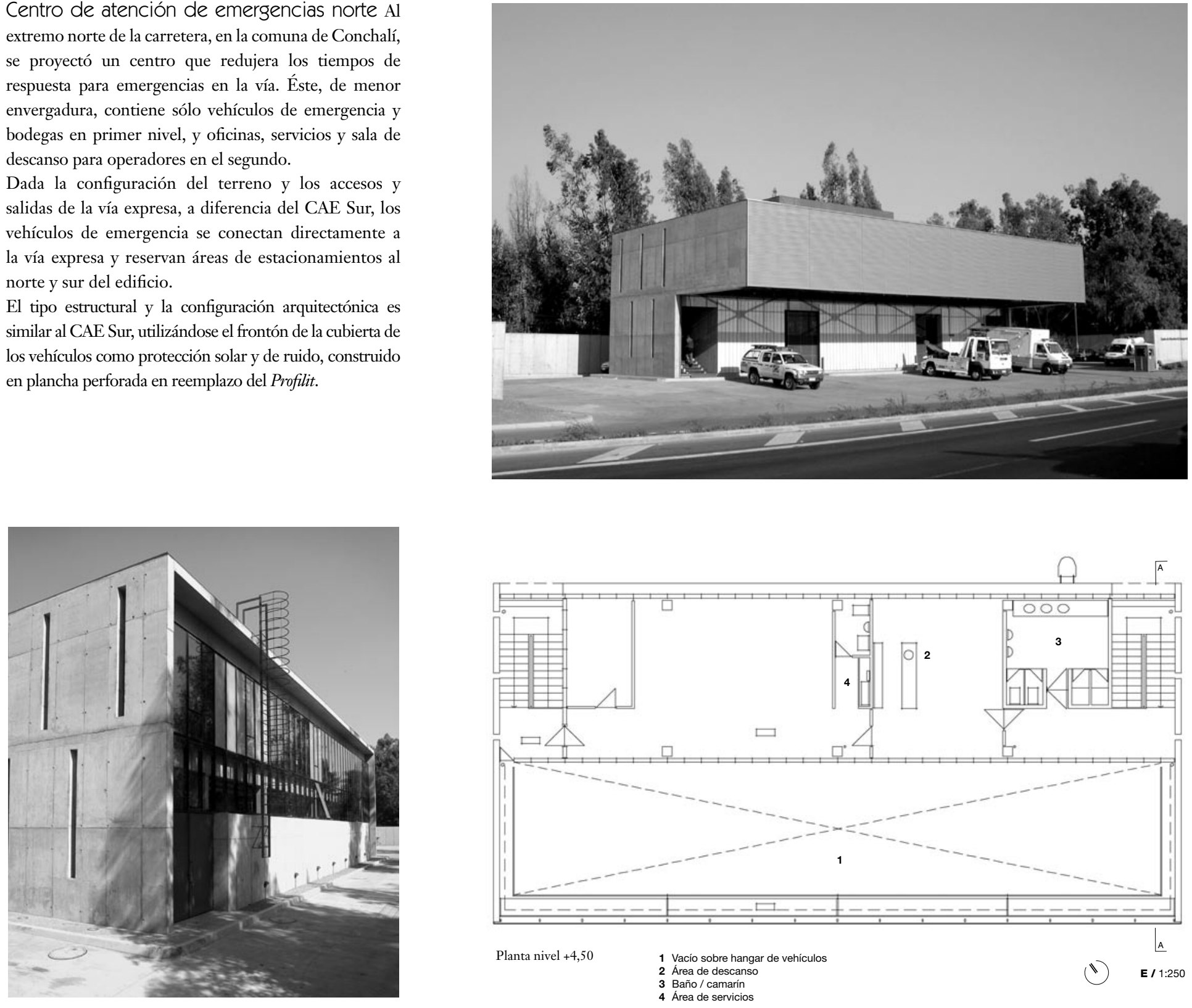

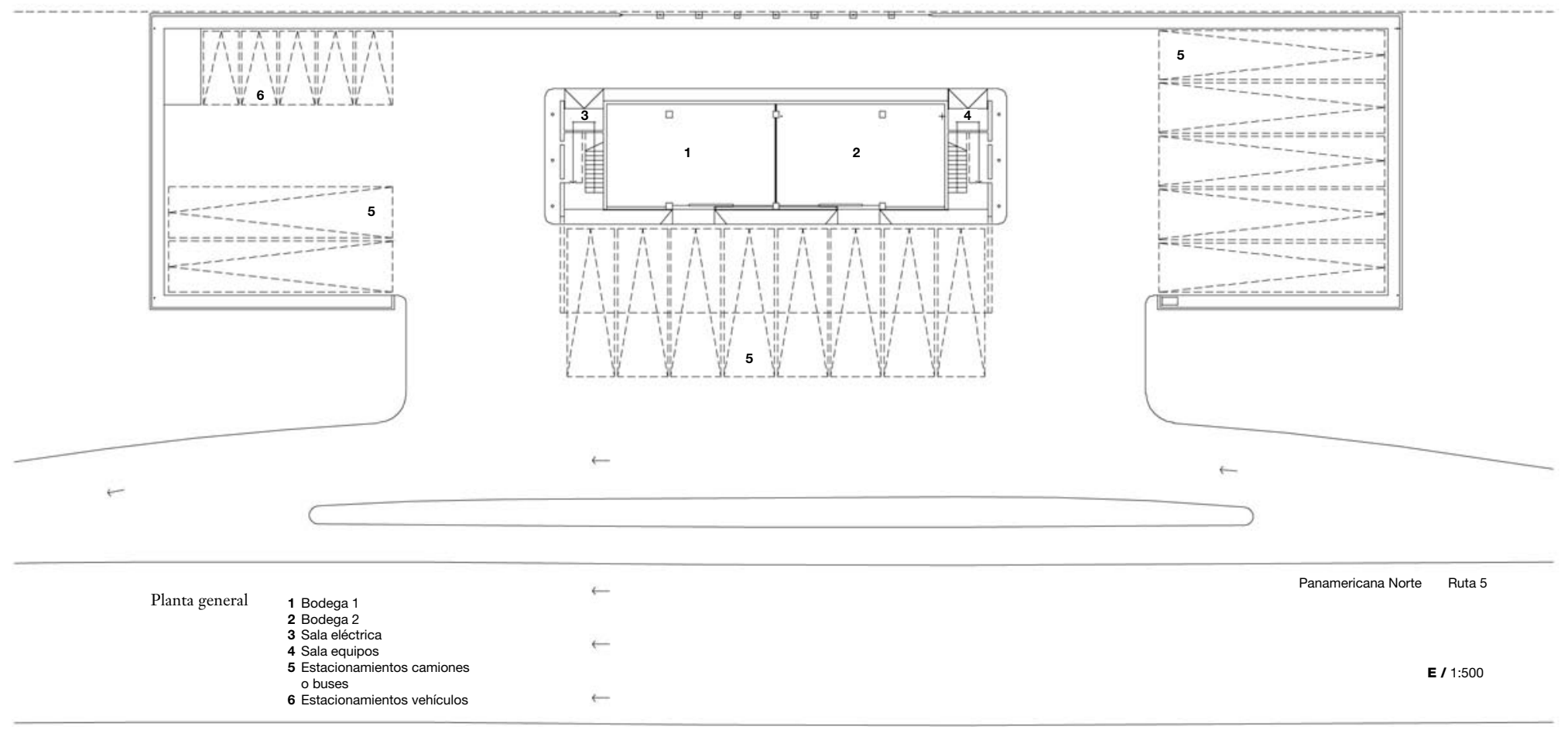




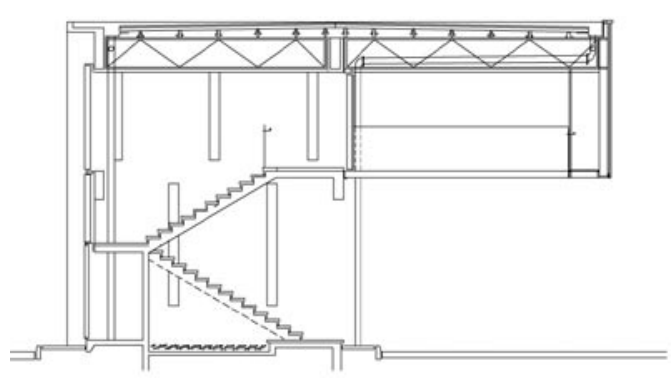

Corte AA
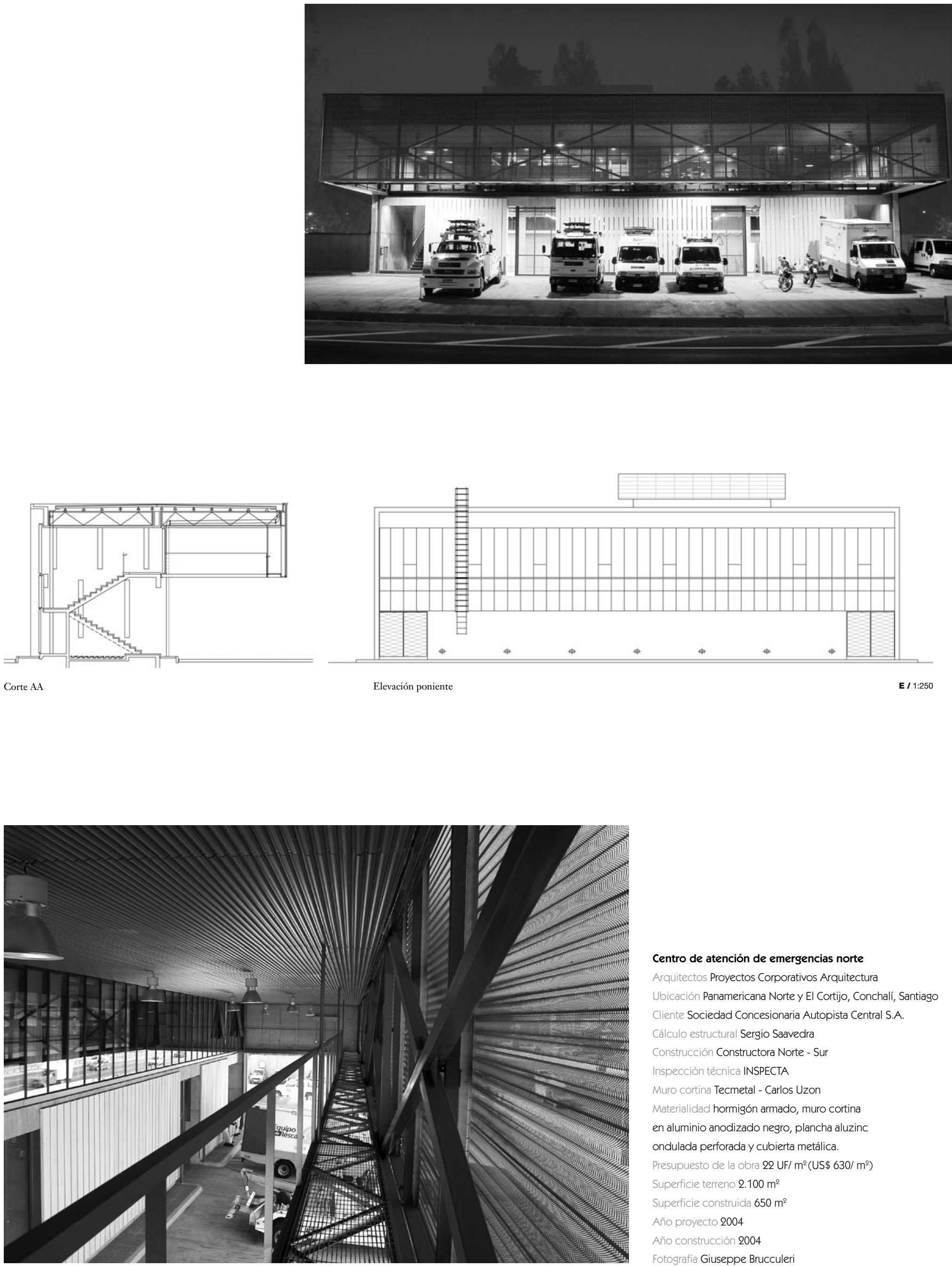

Centro de atención de emergencias norte

Arquitectos Proyectos Corporativos Arquitectura

Ubicación Panamericana Norte y El Cortijo, Conchalí, Santiago Cliente Sociedad Concesionaria Autopista Central S.A. Cálculo estructural Sergio Saavedra

Construcción Constructora Norte - Sur Inspección técnica INSPECTA

Muro cortina Tecmetal - Carlos Uzon Materialidad hormigón armado, muro cortina en aluminio anodizado negro, plancha aluzinc ondulada perforada y cubierta metálica.

Presupuesto de la obra 22 UF/ m²(US\$630/ m²)

Superficie terreno $2.100 \mathrm{~m}^{2}$

Superficie construida $650 \mathrm{~m}^{2}$

Año proyecto 2004

Año construcción 2004

Fotografía Giuseppe Brucculeri 


\section{Centro de atención de emergencias sur}

La concesionaria modificó el trazado de la caletera oriente, acercándola a la vía expresa de tal forma de conseguir un paño de terreno adosado al edificio corporativo; en él se construirían oficinas, estacionamientos y bodegas de mantenimiento de pistas y de seguridad vial. El paño de $250 \mathrm{~m}$ de frente y aproximadamente $20 \mathrm{~m}$ de ancho determinó el partido a seguir: dispusimos un cuerpo de $210 \mathrm{~m}$ de largo y $12 \mathrm{~m}$ de ancho sobre la línea de edificación de la caletera, dejando una calle de servicio interior.

En el primer nivel se emplazaron el nuevo centro de control de tráfico, las bodegas y los estacionamientos; en el segundo, un cuerpo de oficinas para mantenimiento, seguridad, oficina técnica e inspección fiscal. El edificio se estructura en base a pilares de hormigón armado, modulados cada $8 \mathrm{~m}$, que sostienen una losa colaborante y la cubierta metálica.

En la fachada a la carretera se proyectó un zócalo en hormigón armado y una ventana corrida protegida del excesivo asoleamiento poniente y del ruido de la carretera con una sobrefachada en canoas de cristal (Profilit). La misma fachada cierra el patio de estacionamiento de vehículos siniestrados, abarcando la totalidad del frente.

Este elemento continuo resulta acorde con la simpleza y linealidad de la carretera y su velocidad y se contrasta con la expresión de los distintos materiales y programas que se orientan a la calle interior (madera laminada, mallas de metal desplegado, Profilit y termopaneles de fachada) bajo un gran alero que unifica el conjunto.

$\mathrm{Al}$ ser un equipamiento que opera 24 horas y de gran importancia para la operación de la carretera, se implementó una iluminación muy simple pero de mucha presencia. Son dos líneas paralelas a lo largo de la fachada: una azul que se difunde por las canoas de cristal y otra blanca sobre el muro de hormigón que reemplazan en este tramo la postación para la iluminación de la vía.

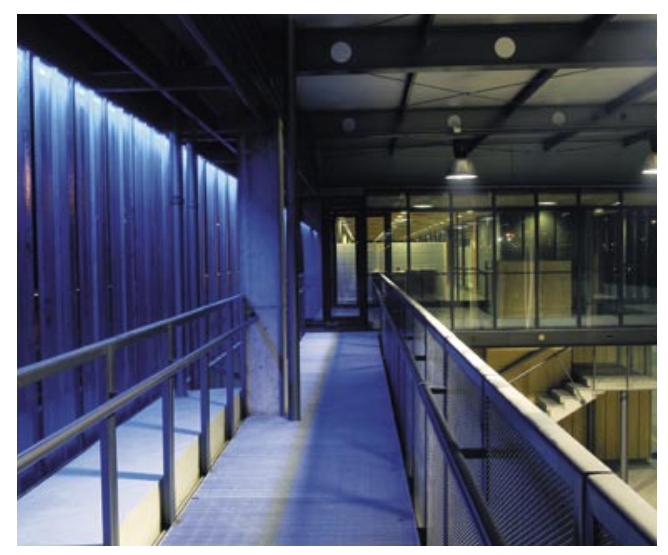

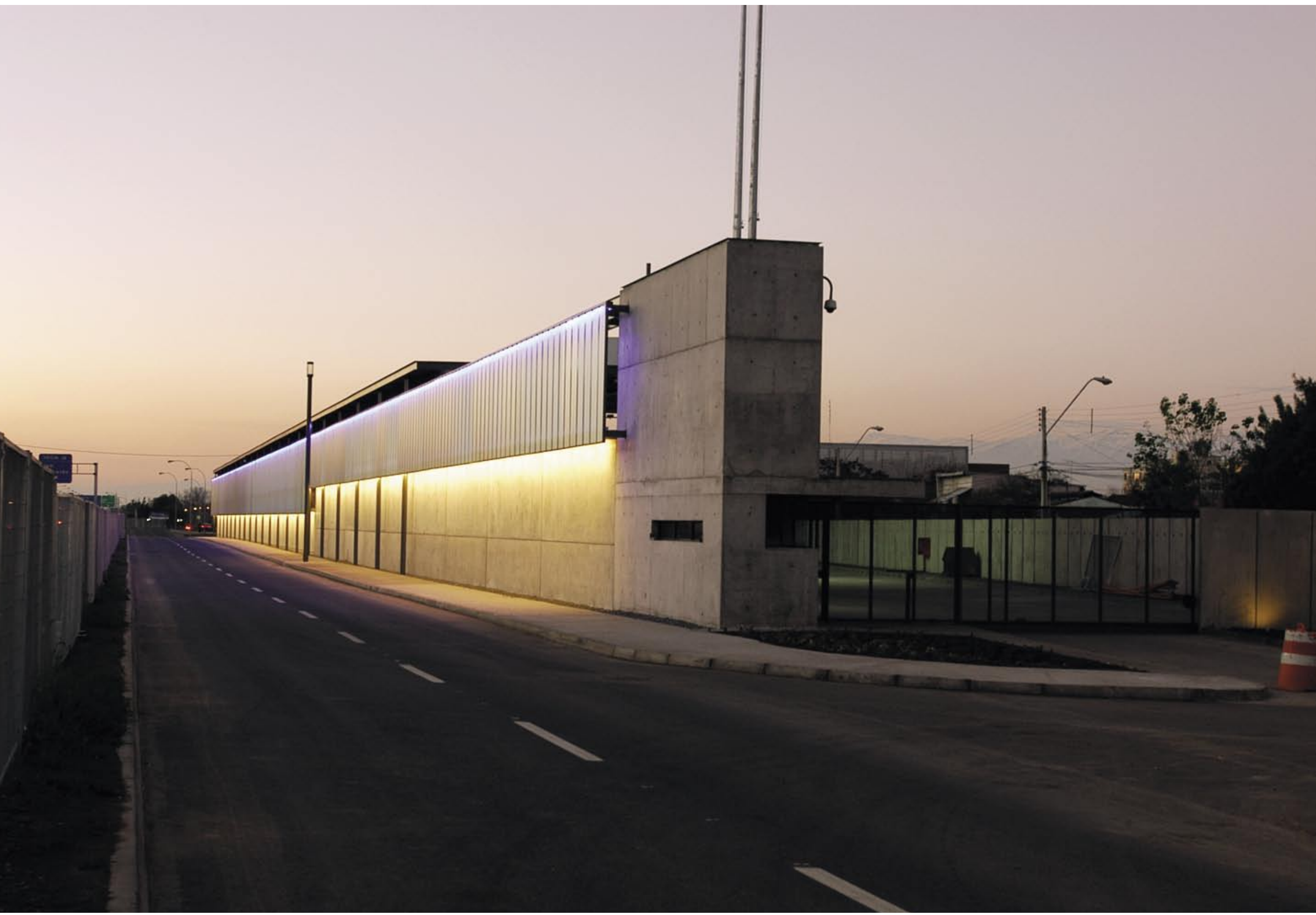



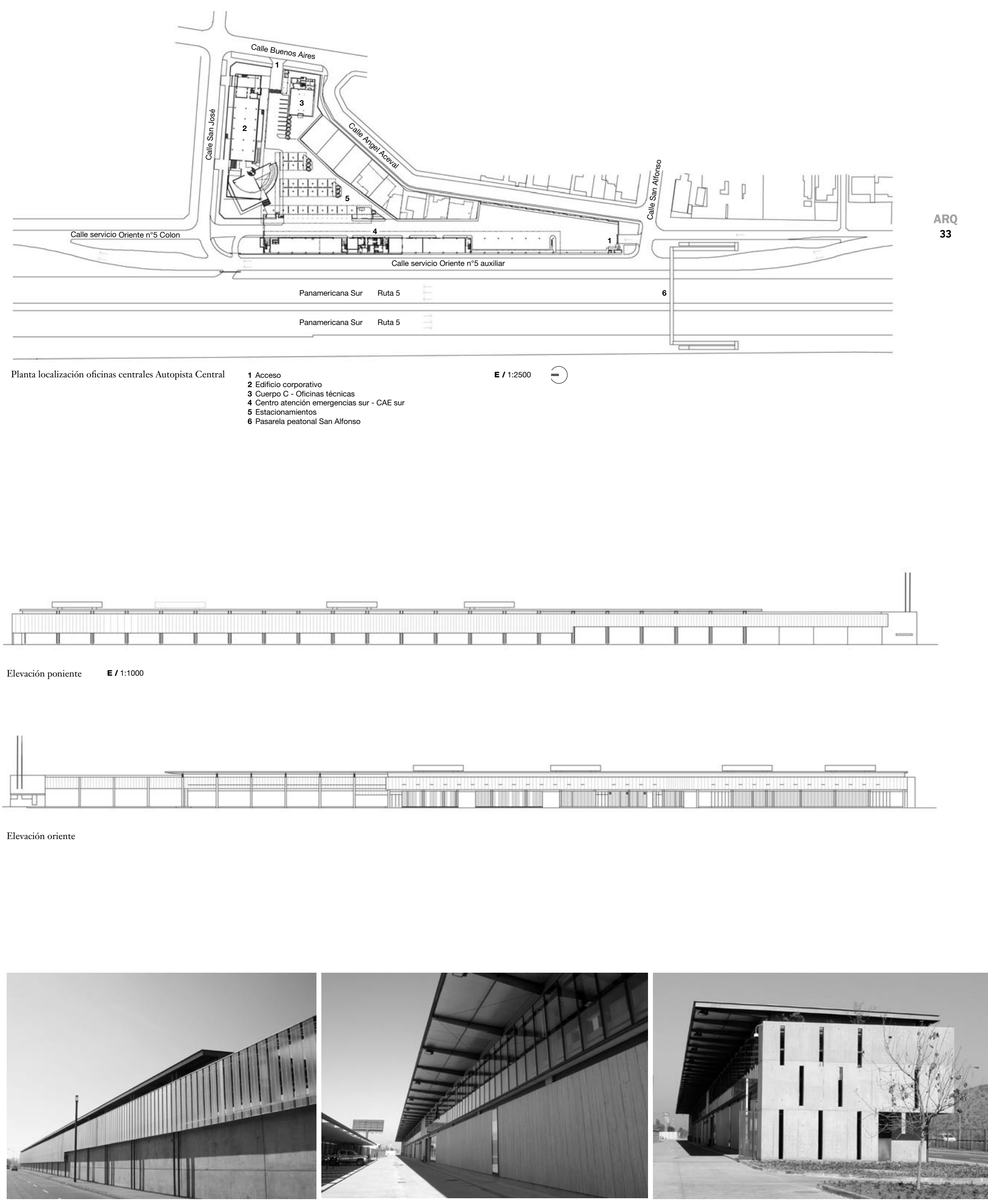
6 Patio maniobras

7 Estacionamientos

8 Oficinas

0 Área de descanso
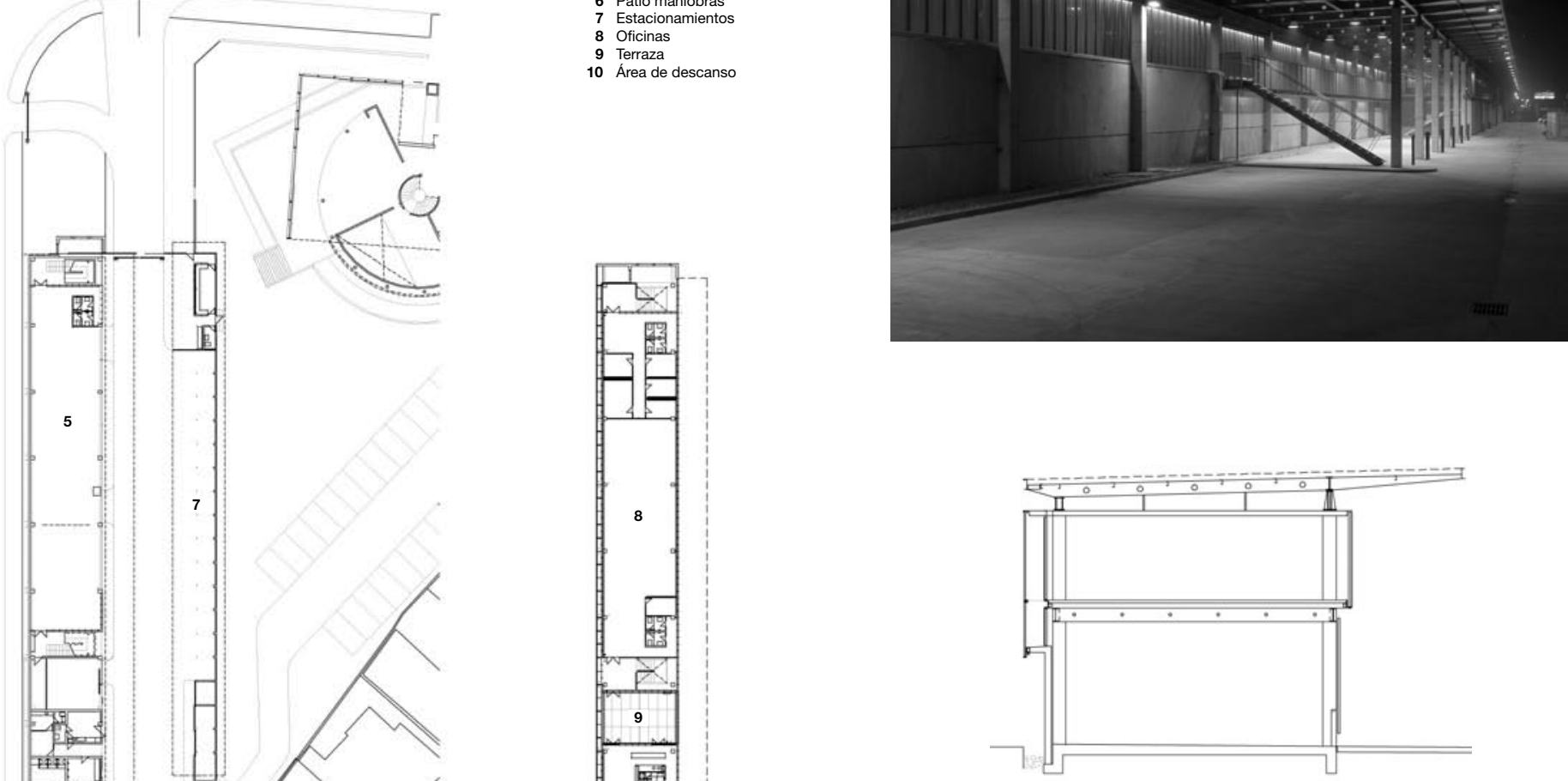

Corte AA

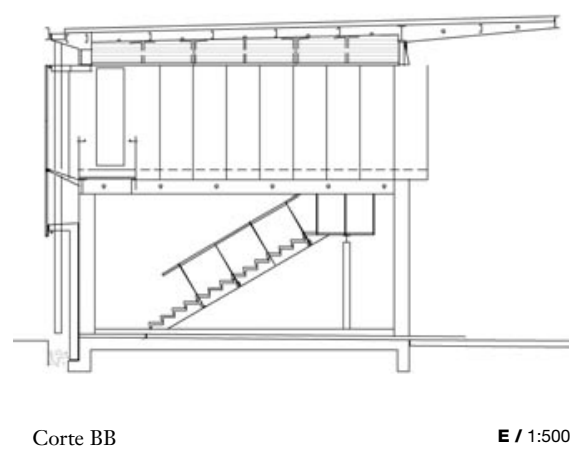

\section{Centro de atención de emergencias sur}

Arquitectos Proyectos Corporativos Arquitectura

Ubicación Panamericana Sur y San José, San Bernardo, Chile Cliente Sociedad Concesionaria Autopista Central S.A. Cálculo estructural Julio Muñoz Construcción Inarco - Ingevec Inspección técnica Inspecta Proyecto eléctrico Penta Climatización Enertec Mecánica de suelos Marcelo Vargas Muro cortina y Profilit Tecmetal - Carlos Uzon Materialidad hormigón armado, muro cortina en aluminio anodizado negro, perfiles Profilit y cubierta metálica Presupuesto de la obra 25 UF/ $\mathrm{m}^{2}\left(\mathrm{US} \$ 716 / \mathrm{m}^{2}\right)$ Superficie terreno $5.800 \mathrm{~m}^{2}$ Superficie construida $2.850 \mathrm{~m}^{2}$ Año proyecto 2003 Año construcción 2004 


\section{Vespucio Norte Express}

\section{Edificio Corporativo}

Para la concesionaria del tramo de Avda. Américo Vespucio entre El Salto y la Ruta 68 desarrollamos las casetas técnicas y su edificio corporativo. Las primeras son muy similares a las de Autopista Central y responden a los mismos conceptos. El edificio corporativo, en cambio, responde a conceptos de diseño y requerimientos particulares.

El edificio se emplaza en un predio de $5.000 \mathrm{~m}^{2}$ en el Parque Industrial ENEA, con frente al trébol que conecta el Aeropuerto Arturo Merino Benítez con Américo Vespucio. Tanto el plazo de desarrollo como el presupuesto de inversión eran ajustados y debían respetarse rigurosamente. Junto con ello el requerimiento de nuestro cliente era de proyectar espacios flexibles, adaptables a las modificaciones programáticas habituales, y que resultaran en espacios de trabajo ventilados, bien iluminados, bien relacionados y que además lograra una clara presencia sobre la carretera. El programa solicitado consideraba las oficinas generales, el centro de control de tráfico, las oficinas de la inspección fiscal, bodegas, estacionamientos y oficinas para atención de pistas y un casino.

Sobre el terreno casi cuadrado dispusimos dos cuerpos paralelos que forman un patio entre ellos. El cuerpo principal, frente al trébol en la faja poniente, contiene las oficinas generales y el centro de control de tráfico. El segundo cuerpo contiene en su extremo norte las salas de equipos y la cocina en primer nivel, y el casino en el segundo; y hacia el sur, separados por una terraza, las oficinas de inspección fiscal y de pista, sobre bodegas y estacionamiento de vehículos de servicio. Dos aspectos destacables de nuestro proyecto son los siguientes:
Consideramos una estructura de hormigón armado con losas postensadas dispuestas a $5 \mathrm{~m}$, reservando $1 \mathrm{~m}$ para el paquete de piso y el espacio para instalaciones y $4 \mathrm{~m}$ libres interiores. La altura total del volumen llega a los 12,5 m al agregar el zócalo y el antetecho.

Esto permitió que el edificio alcanzara un tamaño adecuado frente a la carretera y apareciera como un volumen de la misma envergadura que sus vecinos de 5 y 6 pisos.

El mismo recurso logró que las plantas del volumen principal, de $20 \times 50 \mathrm{~m}$, se iluminen completamente a través de las fachadas acristaladas de piso a cielo-de $4 \mathrm{~m}$ de altura- y generó una notable espacialidad interior

Otro tema de importancia está ligado a los materiales utilizados, y en especial a la malla de acero inoxidable que cubre la mayor parte de las fachadas del edificio.

La simpleza de la forma general, la escasa diversidad de materiales y de sus encuentros y la rigurosidad de los procesos constructivos permitieron la utilización de materiales de gran calidad, sin aumentar el plazo de ejecución ni la inversión final. Además de los paños de hormigón a la vista que estructuran el edificio y las cintas ventana que lo cierran, se agregaron pocos sistemas o revestimientos adicionales: en los cielos se utilizó un sistema registrable en chapa de mañío de Hunter Douglas, baldosa microvibrada como único pavimento y pizarra en las zonas de baños. Sobre el sistema de termopaneles de fachada se consideró una pantalla de protección solar en malla de acero inoxidable.

Este elemento, desarrollado por diversas fábricas europeas, era el material perfecto para proteger las fachadas del excesivo asoleamiento. $\mathrm{Al}$ ser una trama muy fina, logra equilibrar la transparencia necesaria para una buena visión hacia el exterior con la sombra requerida. Siendo flexible en un sentido, se instala colgada y tensada desde su base sin requerir estructuras adicionales, que ensucian las fachadas. Finalmente el acero inoxidable $316-\mathrm{L}$ asegura que no se deteriorará ni sufrirá alteraciones a lo largo del tiempo.

Este material era conocido por los mandantes, al igual que su precio, lo que hacía completamente imposible considerarlo para el proyecto.

Recordamos que existe una fábrica de mallas que produce tejidos de acero inoxidable para cintas transportadoras, RGM, y nos contactamos con la empresa. Luego de estudiar las mallas más simples producidas en Europa -que básicamente consisten en barras de acero horizontales, colgadas de un trenzado de cables- vimos que el tejido para las cintas transportadoras tenía el mismo comportamiento que el trenzado de cables y que podía reemplazarlo. Produjimos una serie de muestras para definir la distancia entre colgadores, el diámetro de las barras y el espacio entre ellas, hasta llegar a una malla que entrega prestaciones comparables a las europeas. Finalmente diseñamos el sistema de montaje con sus herrajes respectivos. Hunter Douglas se interesó en el producto y se hizo cargo de su instalación. Los reflejos de la luz natural y los efectos de un buen diseño de iluminación artificial, para el que nos asesoramos por Douglas Leonard (también a cargo de la iluminación del CAE Sur de Autopista Central), reforzaron la presencia del edificio sobre la vía.

El costo del producto finalmente resultó ser un tercio de su análogo europeo conocido por el mandante; eso posibilitó utilizarlo. Esta malla está hoy disponible como material para usos arquitectónicos y varios colegas la han considerado en sus proyectos.

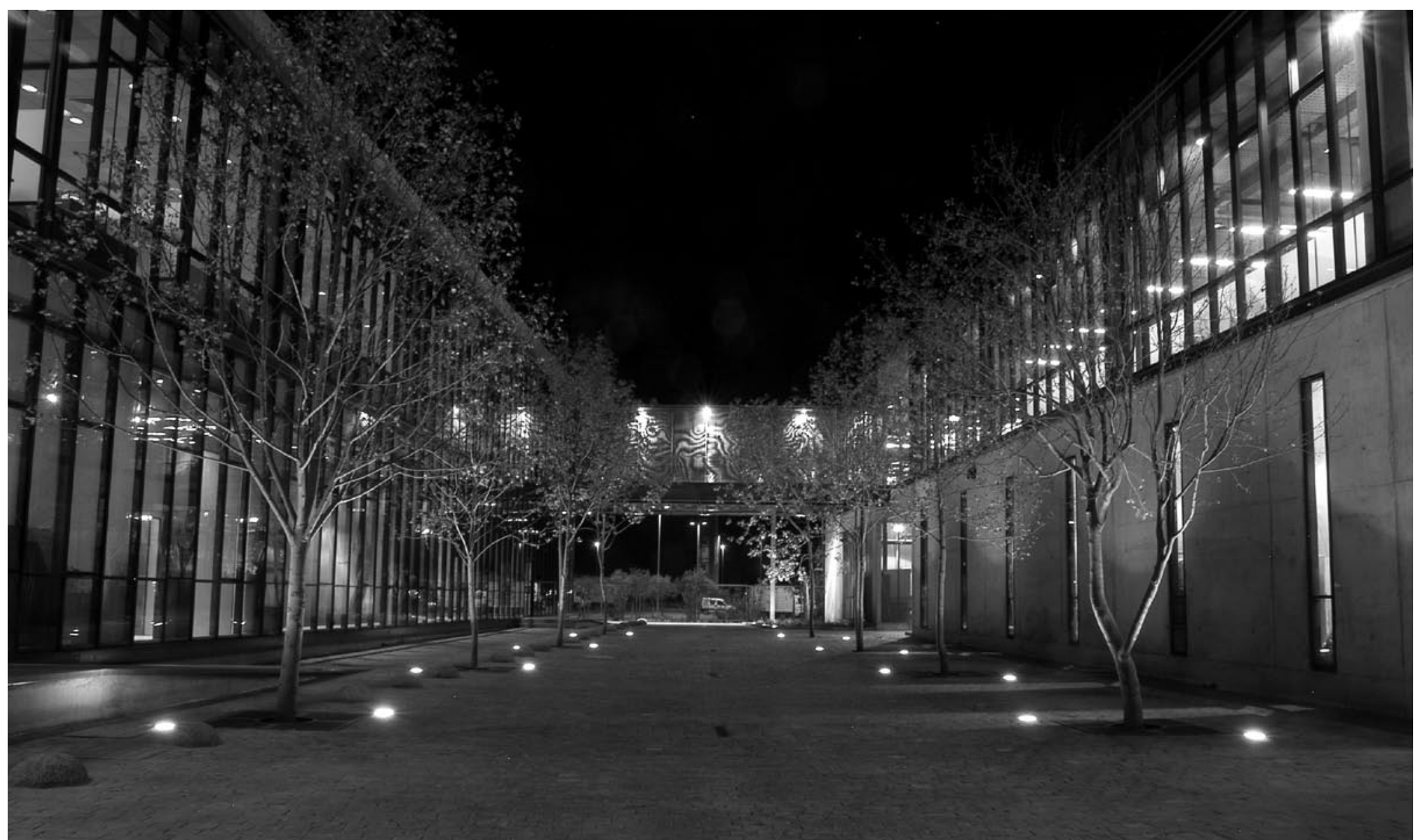




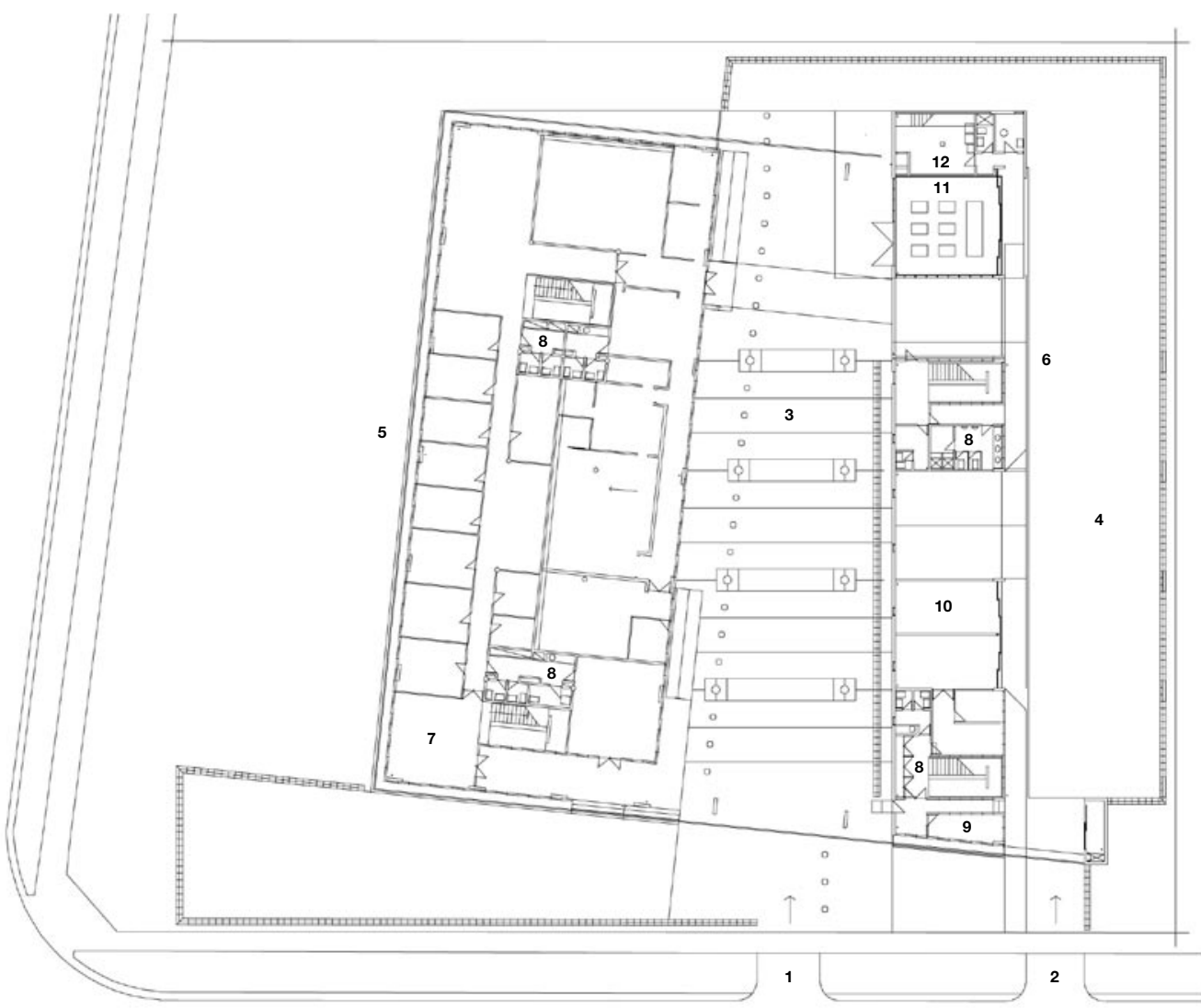

1 Acceso Edificio Corporativo

2 Acceso centro atención

3 Patio interior

4 Patio maniobras

5 Cuerpo A
6 Cuerpo B

6 Cuerpo B

8 Servicios

10 Bodega

Area equipos técnicos

Planta emplazamiento

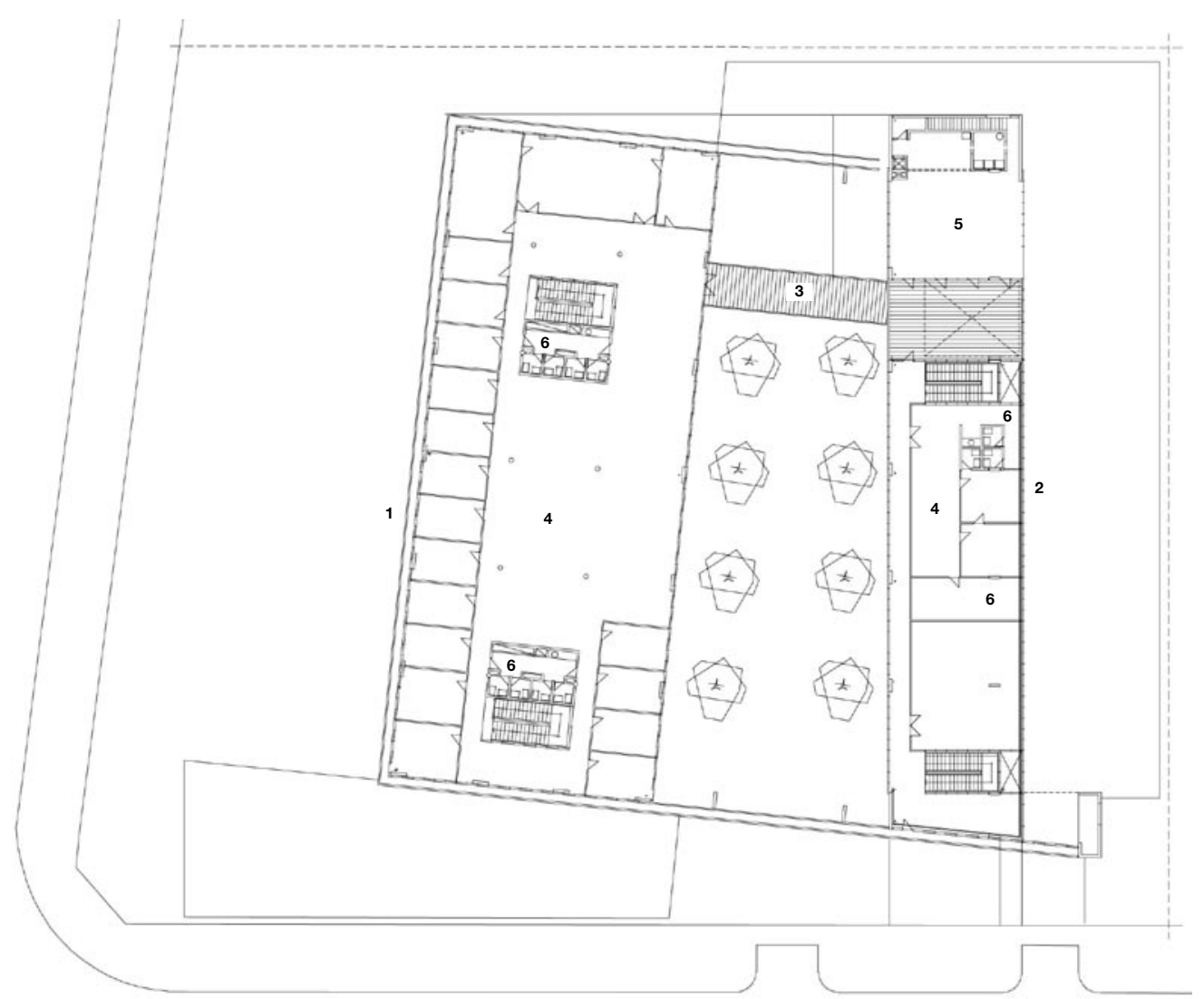

$\begin{array}{ll}1 & \text { Cuerpo A } \\ 2 & \text { Cuerpo B } \\ & \end{array}$

3 Pasarela

5 Oficinas
Casino

$E / 1: 500$ (I) 

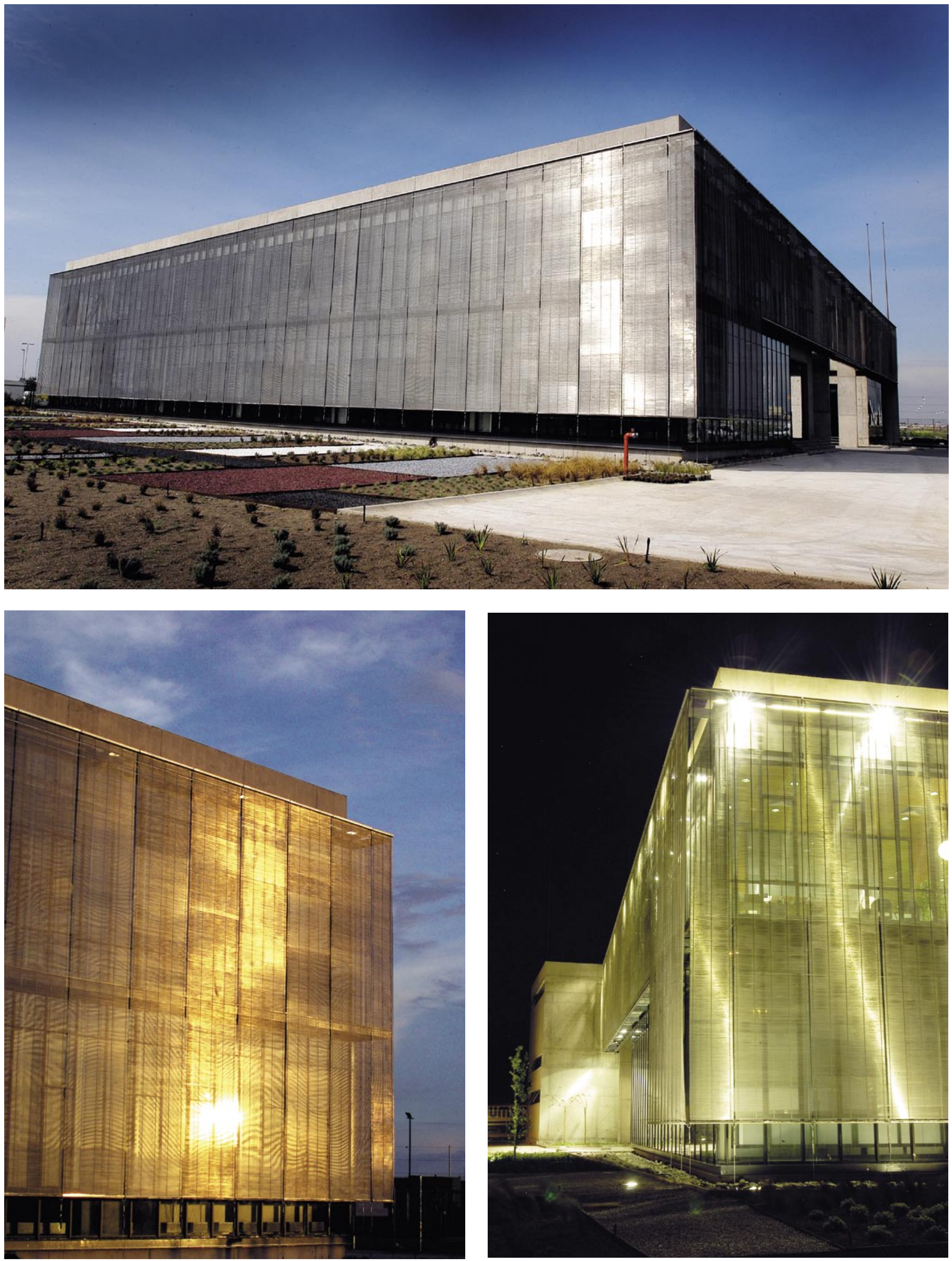


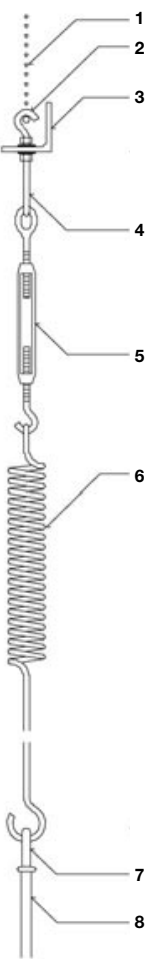

A Detalle corte fijación inferior pantalla. Protección solar de acero inoxidable

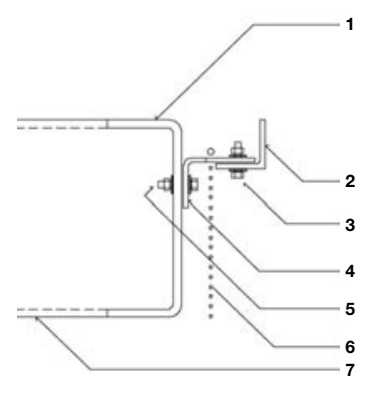

C Detalle corte fijación superior (pantalla metálica)

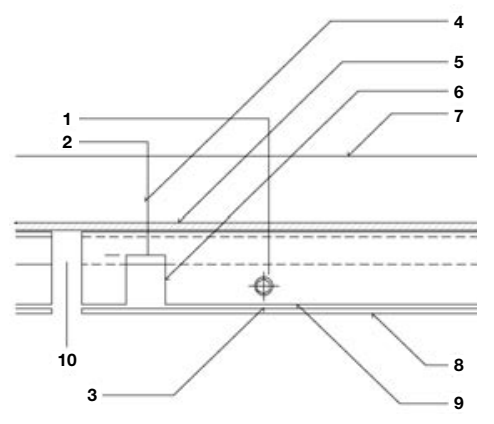

E Detalle planta fijación superior (pantalla metálica)

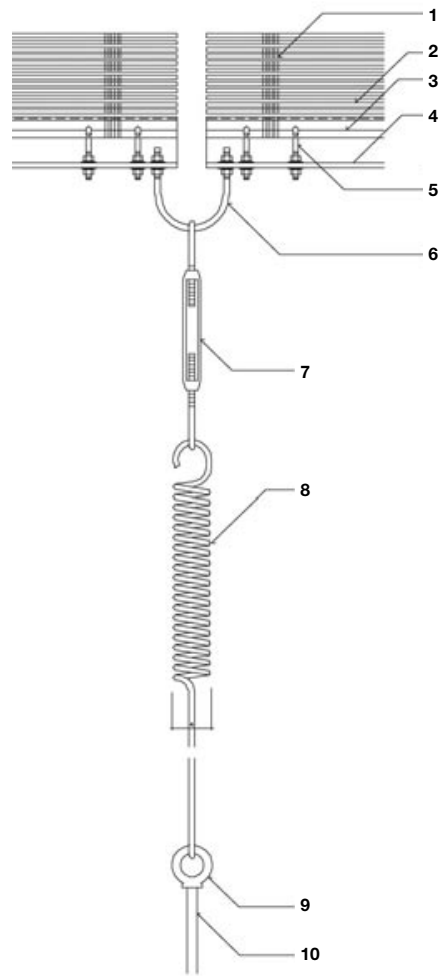

B Detalle elevación fijación inferior

E / 1:10

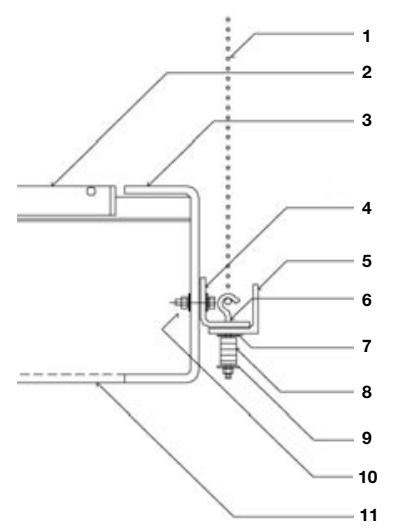

D Detalle corte fijación intermedia (pantalla metálica)

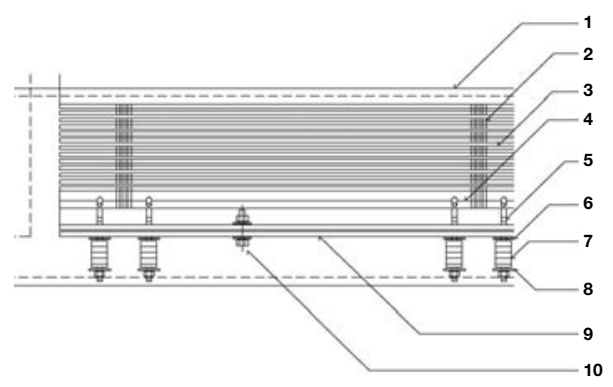

F Detalle elevación fijación intermedia (pantalla metálica)

1 Pantalla metálica protecció solar sg. EE.T. 2 Fijación inferior pantalla metálica cáncamo acero inoxidable AISI $316-\mathrm{L}$, , $3 / 16^{\prime \prime}+$ tuerca contratuerca y golililas.

3 Soporte inferior pantalla metálica protección solar acero inoxidable. AISI 316-L, perfil L 50 × $50 \times 5 \mathrm{~mm}$ (tip.)

4 Perno $U$, barra circular acero noxidable. AISI 316-L, Ø $6 \mathrm{~mm}$.

tuercas, contratuercas y golillas (tip.) Tensor gancho - ojo, acero 3/8" $\times 6$ " (típ.)

6 Resorte espiral, acero inoxidable.
AISI $316-\mathrm{L}$, barra circular $\varnothing 6 \mathrm{~mm}$, ancho $=40 \mathrm{~mm}$, largo $=200 \mathrm{~mm}$,

largo total = $1065 \mathrm{~mm}$ sg. . muestra (tip.) Remate anclaje, cáncan inoxidable. Dim. 3/8" X $11 / 4^{\prime \prime}$ soldado a extremo barra fe (típ.) Anclaje barra lisa fe $\varnothing 12 \mathrm{~mm}$

fijación a fundación Sikadur 31 ,

1 Solera de fachada superior perfil C Fe $200 \times 75 \times 8 \mathrm{~mm}$ (tip.) 2 Perfil remate superior, acero inoxidable, AISI 316-L, perfil $L 50 \times 50 \times 5 \mathrm{~mm}$ sg. detalle (tip.)
Fijación perfil remate superior, perno acero inoxidable Parker perno acero inoxidable Parker
$\varnothing 5 / 16 " \times 1$ " hilo UNC c/golilla (tip. 4 Soporte superior pantalla metálic protección solar perfil L Fe $75 \times$ $50 \times 5 \mathrm{~mm}$, plegado especial (típ) acero inoxidable Parker, Ø $3 / 8^{\prime \prime} \times$ 1 acero inoxidable Parker $114^{\prime \prime}$, hilo UNC c/golilla (tip.) 6 Pantalla metálica protección solar sg. EE.T.

7 Conector solera de fachada intermedia perfil tubular Fe $200 \times$
$100 \times 3 \mathrm{~mm}$ sg. cálculo (tip.)

1 Fijación perfil remate 2 Fijación soporte Fijación perfil remate superior, perno acero inoxidable Parker $\varnothing$ 4 Fijación soporte superior P (típ.) acero inoxidable. Parker \%\%c $3 / 8$ " x $11 / 4$ " hilo UNC c/golilla (tip.) 5 Solera de fachada superior perfi C Fe $200 \times 75 \times 8$ mm (típ.) Destaje en solera para

7 Solera de fachada superior perfil $\mathrm{CFe} 200 \times 75 \times 8 \mathrm{~mm}$ (tip.) 8 Perfil remate superior, acero inoxidable, AISI 316-L, perfil L 50
$\times 50 \times 5 \mathrm{~mm}$ sg. detalle (tip.) $\times 50 \times 5 \mathrm{~mm}$ sg. detalle (tip.).
9 Soporte superior pantalla

metálica protección solar perfil

metalica proteccion solar pert
L Fe $75 \times 50 \times 5 \mathrm{~mm}$ plegado

especial (típ)

10 Separación entre módulos
1 Cadena de espiras acero $15 \mathrm{~mm} \varnothing$ espiras $=1 \mathrm{~mm}$ (tip.). 2 Pasador barra circular acero inoxidable, AISI 316-L $\varnothing 4 \mathrm{~mm}$ (tip.) Pasador remate pantalla, barra AISI $316-\mathrm{L} \varnothing 8 \mathrm{~mm}$ (tip). 4 Soporte inferior pantalla metálica protección solar acero inoxidable, AISI 316-L, perfil L L $50 \times 50 \times 5 \mathrm{~mm}$ (típ.)
5 Fijación inferior pantalla metálica 5 cáncamo acero inoxidable AISI 316-L, Ø $8 / 16 "$ " tuerca, contratuerca y golillas. Largo $=60 \mathrm{~mm}$ (tip.).

6 Perno U, barra circular acero inoxidable, AISI 316-L $\varnothing 3 / 8 "$ " + 7 tuercas, contratuercas y golillas inoxidable, AISI 316-L,

dim. 3/8" x 6" (típ.) 8 Resorte espiral, acero inox. AIS ancho $=40 \mathrm{~mm}$, largo $=200 \mathrm{~mm}$ largo total = $1065 \mathrm{~mm} \mathrm{sg}$ Remate ancl

mecánico con hombro, ace inoxidable. Dim. 3/8" x $11 / 4$ ", soldado a extremo barra $\mathrm{Fe}$ (típ.) Anclaje barra lisa Fe $\varnothing 12 \mathrm{~mm}$,

terminación pintura sg. EE.TT. (tip.)
D

1 Pantalla metálica protección solar sg. EE.TT. 2 Circulación servicio parrilla de piso metálica rectangular, sg. detalles

Sg. detalles
Solera de fachada intermedia perfil H Fe $200 \times 50 \times 6$ mm (tip.) 4 Soporte intermedio pantalla metálica protección solar perfl
L Fe $50 \times 50 \times 5 \mathrm{~mm}$ (típ.) 5 Perfil remate inferior, acero inoxidable, AISI 316-L, pe

6 Fijación inferior pantalla metálica, gancho acero inoxidable. Barra circular, $\varnothing 6 \mathrm{~mm}$, largo $=100 \mathrm{~mm}$ (tip.) Golilla acero inoxidable, stampada conica, Ø25 mm Resorte sgpiral acero inoxidable AISI 316-L, barra circular Ø $2 \mathrm{~mm}$, alto $=50 \mathrm{~mm}$, ancho = $20 \mathrm{~mm}$, paso $=2,5 \mathrm{~mm} \mathrm{sg}$. muestra (tip.) muestra (tip.)

10 Fijación soporte intermedio, perno acero inoxidable Parker Ø $3 / 8^{\prime \prime} \times 1$ 1/4" hilo UNC c/golilla (tip) 11 Conector solera de fachada $100 \times 3 \mathrm{~mm}$ sg. cálculo (típ.)

\section{F}

1 Solera de fachada intermedia perfil H Fe $200 \times 50 \times 6$ mm (tip.) 2 Cadena de espiras acero inoxidable AISI 316-L, ancho $15 \mathrm{~mm} \varnothing$ espiras $1 \mathrm{~mm}$ (tip.). inoxidable AISI 316-L, Ø $4 \mathrm{~mm}$ (tip.) 4 Pasador remate pantalla, barra circular acero inoxidable AIS 316-L. Ø $8 \mathrm{~mm}$ (típ.)

5 Fijación inferior pantalla metálica, circular, $\varnothing 6 \mathrm{~mm}$, largo $=100 \mathrm{~mm}$ (tip) 6 Golilla acero inoxidable estampada cónica, $\varnothing 25 \mathrm{~mm}$ e $=1 \mathrm{~mm}$ sg. muestra (tip.)

7 Resorte espiral acero inoxidable, A paso $=2.5 \mathrm{~mm}$, muestra (tip) 8 Golilla acero inoxidable estampada cónica, $\varnothing 25 \mathrm{~mm}$ $\mathrm{e}=1 \mathrm{~mm}$ sg. muestra (tip.)
Perfil remate inferior, acero 9 Perfil remate inferior, acero $20 \times$ inoxidable AISI 304, perfil
$50 \times 5 \mathrm{~mm}$ sg. detalle (tip.)

10 Fijación perfil remate intermedio perno acero inoxidable Parker $~$
$5 / 16 "$ x 1 " hilo UNC c/golilla (típ.) 

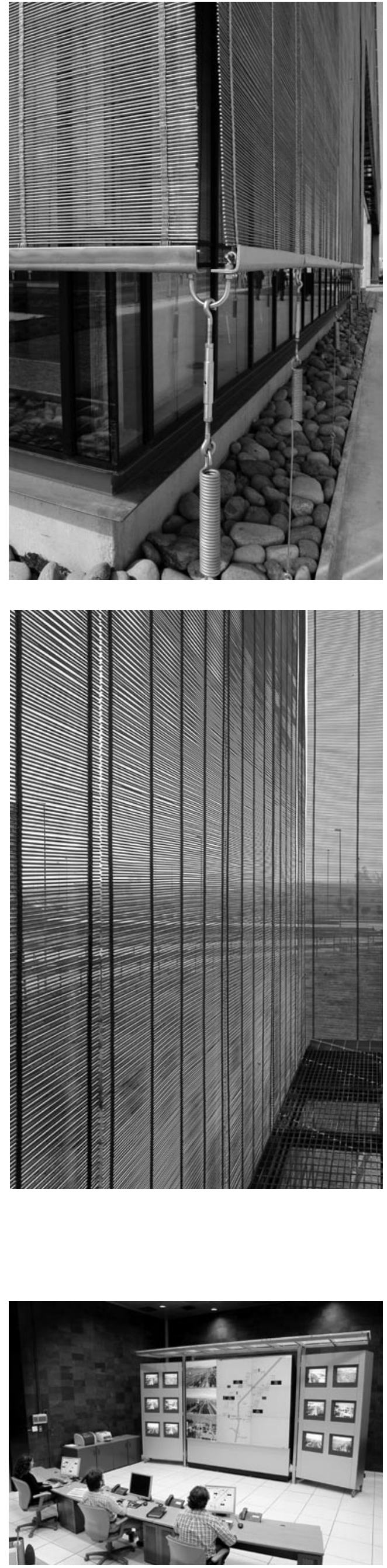

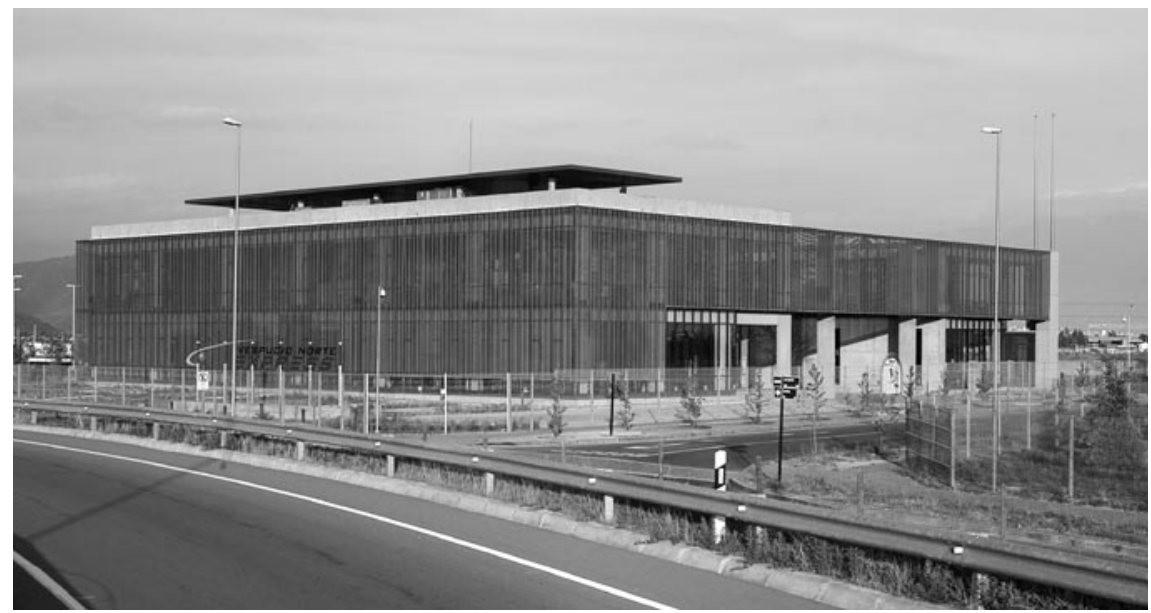

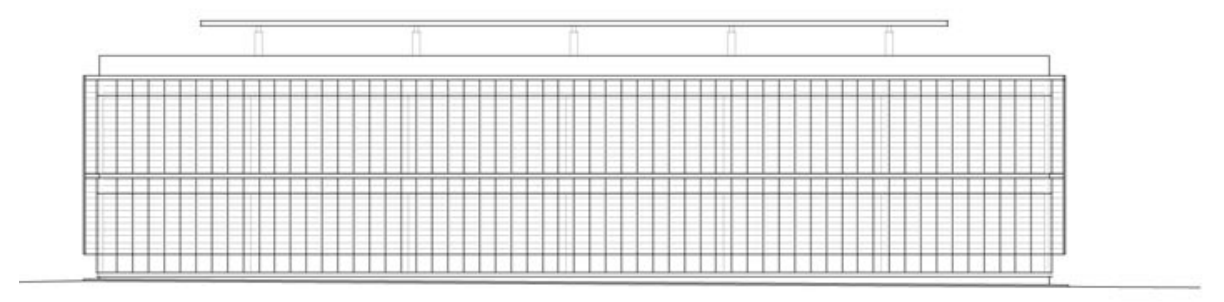

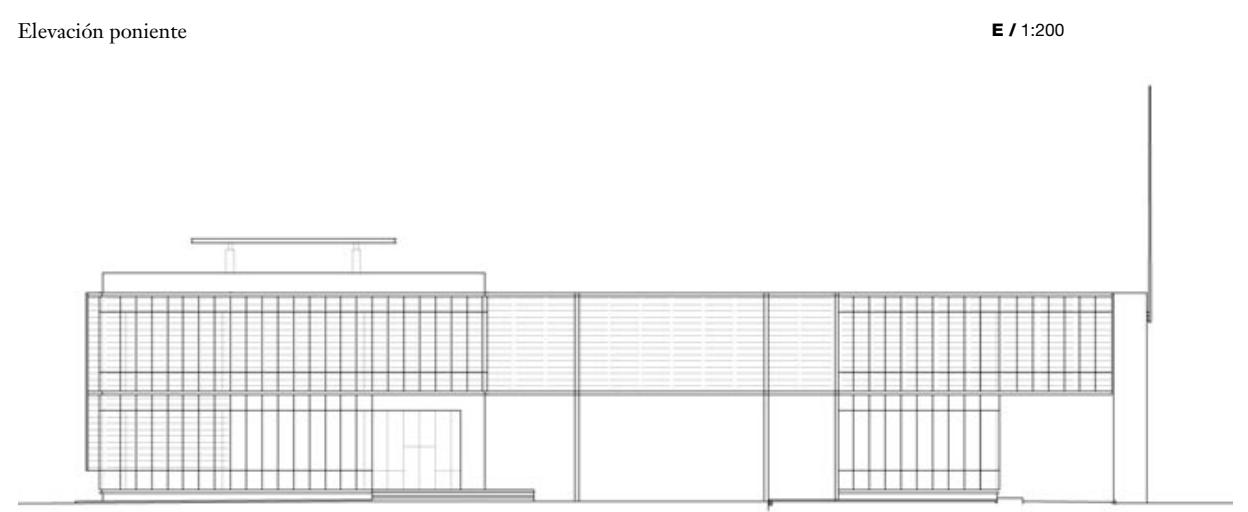

Elevación sur

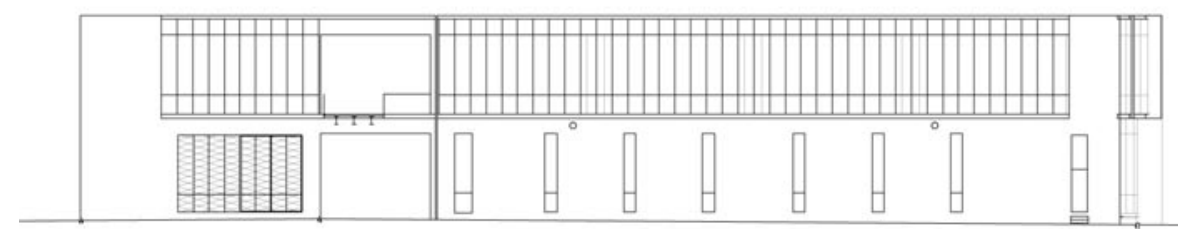

Elevación patio interior

\section{Edificio Corporativo}

Arquitectos Proyectos Corporativos Arquitectura Ubicación Parque Industrial ENEA, Américo Vespucio Norte, Pudahuel, Chile

Cliente Sociedad Concesionaria Vespucio Norte Express S.A. Cálculo estructura Gatica - Giménez

Construcción Constructora ISA

Revisor independiente Daniel Costa

Instalaciones sanitarias Giaretti Hnos.

Proyecto eléctrico Ipel

Climatización Enertec

Mecánica de suelos Marcelo Vargas
Muro cortina y tabiquería cristal Tecmetal - Carlos Uzon Materialidad hormigón armado, muro cortina en termopanel y aluminio anodizado negro, malla de acero inoxidable multibarrete

Malla de acero RGM - Adriana Antillo

Presupuesto de la obra 28 UF/ $\mathrm{m}^{2}$ (US $\$ 802 / \mathrm{m}^{2}$ )

Superficie terreno $5.000 \mathrm{~m}^{2}$

Superficie construida $2.850 \mathrm{~m}^{2}$

Año proyecto 2003

Año construcción 2004

Fotografía Giuseppe Brucculeri 